\title{
Entrevista com Paulo Renato Souza: reflexões sobre a Revolução Gerenciada
}

\author{
Interview with Paulo Renato Souza: reflections about Managed Revolution
}

Entrevista con Paulo Renato Souza: reflexiones sobre la Revolución Gestionada

EVERALDO DA SILVA*

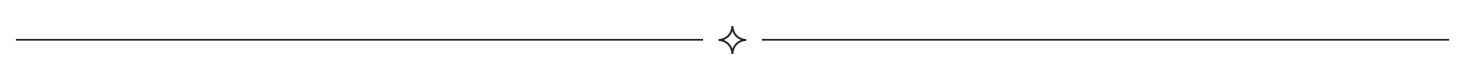

O professor Paulo Renato Souza nasceu em Porto Alegre, Rio Grande do Sul, no dia 10 de setembro de 1945. Economista renomado, formado pela Universidade Federal do Rio Grande do Sul, obteve seu Mestrado pela Universidade do Chile e seu Doutorado pela Universidade Estadual de Campinas - UNICAMP. Foi professor titular do Instituto de Economia da Universidade Estadual de Campinas. Ministrou cursos também na Universidade Federal do Rio de Janeiro, Universidade do Chile, Católica de São Paulo e Católica do Chile. Além de professor, foi pesquisador visitante na École de Hautes Études en Science Sociales, em Paris, e no Institute for Advanced Study, em Princeton, nos Estados Unidos. Fora da área acadêmica, foi gerente de operações e vice-presidente do Banco Interamericano de Desenvolvimento. Nos anos 1980, foi reitor da Universidade Estadual de Campinas. Secretário de Educação do Estado de São Paulo e presidente da Companhia de Processamento de Dados do Estado de São Paulo. Na década de 1970, foi especialista das Nações Unidas em questões de empregos e salários e diretor adjunto do Programa Regional do Emprego para a América Latina e o Caribe. Foi um dos fundadores do PSDB, ministro da Educação no governo Fernando Henrique Cardoso (entre 1995 e 2002) e secretário de Educação do Estado de São Paulo no governo José Serra (entre 2009 e 2010) e no governo Franco Montoro (entre 1984 e 1986). Em 2005, publicou o livro A revolução gerenciada: educação no Brasil, 1995-2002. Dentre as suas maiores realizações à frente do Ministério da Educação estão o Exame Nacional do Ensino Médio (Enem)

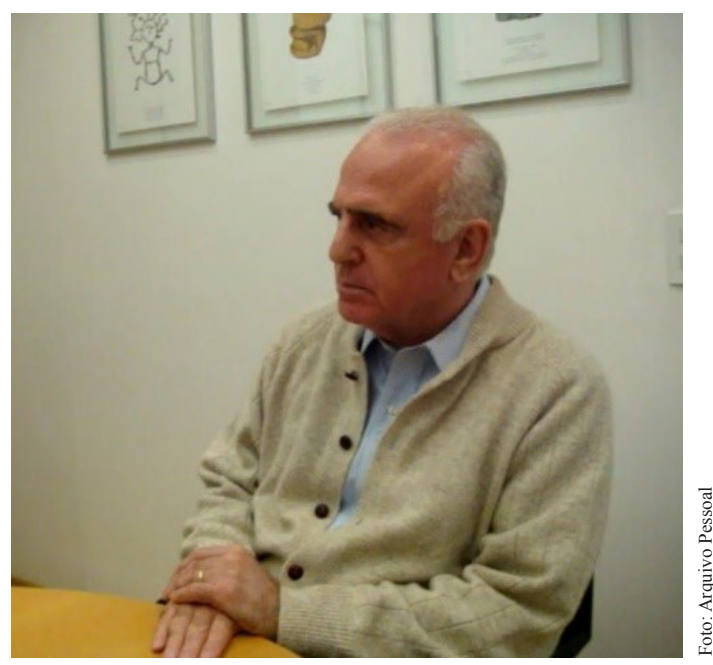

Professor PAulo Renato Souza

e o Sistema Nacional de Avaliação da Educação Básica (Saeb). O ex-ministro Paulo Renato Souza faleceu aos 65 anos, em 2011, não estava ocupando nenhum cargo público e atuava como consultor, principalmente em projetos ligados à educação, em empresas da iniciativa privada. O entrevistado conhece bem área a de educação, economia do desenvolvimento e economia do trabalho e nesta entrevista - concedida em São Paulo, na Paulo Renato Souza Consultores, em julho de 2009 -, apontou aspectos relevantes sobre equidade, avaliação, ensino, pesquisa, extensão e EAD, bem como sobre o mercado de educação superior. 


\section{A ENTREVISTA}

- Everaldo: Bom, professor, faço doutorado na Universidade Federal de Santa Catarina - UFSC, na área de Sociologia Política. O tema é o ensino superior no período de governo Fernando Henrique Cardoso, e o objetivo da tese não é fazer uma crítica ao período, mas sim descrevê-lo e mostrar sua importância para o desenvolvimento da educação no país. Primeiramente, gostaria que o senhor falasse sobre a atuação do Ministério da Educação na época. Qual era seu objetivo central? Era a abertura de mais vagas para o ensino superior, já que a universidade pública não atendia à demanda?

$\square$ Paulo Renato: Você leu o Mãos à obra, não? Porque nele há um capítulo sobre a educação. Lá está muito claro o que queríamos fazer antes de entrar no governo. Tínhamos como objetivo central cuidar da questão da qualidade do ensino básico. Nossa meta, também, era redefinir o papel do ministério, pois isso infelizmente voltou a ocorrer recentemente. Ele se metia a fazer programas, interferindo na responsabilidade que está com os municípios. Achávamos que o ministério deveria ter a função de dar orientação, de definir políticas, de redistribuir recursos com base na equidade e na avaliação. Esse era o objetivo.

- Everaldo: Poderíamos dizer que a proposta era ser uma espécie de órgão regulador?

$\square$ Paulo Renato: Exatamente. Um órgão regulador e executor. Claro, tínhamos a responsabilidade das universidades, mas nosso objetivo primordial era a educação básica. E conseguimos isso. Quer dizer, priorizamos o ensino fundamental. As pessoas perguntam o que fizemos de mais importante no ministério. Bom, o mais visível foi o provão e a avaliação. O mais importante foi o Fundef: a redistribuição dos recursos, levando em consideração o critério de equidade e vinculando-se, também, a questão da valorização do professor. Por isso, o Fundef foi o mais importante.

- Everaldo: Houve um aumento de abertura de instituições.

Paulo Renato: Tínhamos como objetivo, para o ensino superior, criar um sistema de avaliação, vincular recursos destinados às federais, por exemplo, à avaliação e, também, possibilitar a ampliação do segmento particular, as universidades privadas, mas com regras de avaliação. Isso estava claro na proposta. Quando entramos no ministério, o propósito era esse. No entanto, quando se chega ao ministério, o impacto é muito grande porque, embora tivéssemos clara a prioridade para o ensino fundamental, fomos envolvidos em uma série de questões que diziam respeito ao ensino superior e precisamos resolver as demandas mais urgentes.

- Everaldo: O próprio orçamento do ensino superior é...

Paulo Renato: O MEC é o órgão responsável pelas universidades federais. Então, é natural que a maior parte do orçamento vá para o ensino superior. Se observarmos o financiamento da educação no Brasil, veremos que ele é predominantemente de responsabilidade dos estados e dos municípios. Eles se dedicam primordialmente ao ensino básico. No conjunto do financiamento, a parte do ministério é a menor. Então, olhando o todo, percebe-se que a distorção não é assim tão grande. No entanto, reconhecemos que boa parte do orçamento que tínhamos se destinava ao ensino superior. Quando assumimos, fomos bombardeados por uma infinidade de pedidos e por que não dizer pressões, para transformar algumas faculdades em universidades. Com que intuito? Dar autonomia para que a expansão ocorresse sem limites preestabelecidos. Em função desse fato, surgiu a necessidade do Provão, como um critério objetivo de qualidade. Assim, procuramos vincular à avaliação todo um sistema automático de expansão. Ou seja, se a instituição fosse bem avaliada, teria permissão para expandir, criar novos cursos. As instituições com avaliação insatisfatória sofriam maior controle, maior supervisão. A ideia foi essa, criar mecanismos automáticos, por isso os centros universitários tinham mais liberdade do que as faculdades isoladas, mas não possuíam tantos requisitos quanto às universidades. Isso sempre vinculado a bons resultados nos processos de avaliação. O sistema de avaliação era complexo, não havia apenas o Provão, havia as visitas às instituições, os relatórios, informações de várias fontes.

- Everaldo: E como o senhor vê os Sinaes?

$\square$ Paulo Renato: Se observarmos os Sinaes em seu conjunto, veremos que é basicamente o que já existia, mas com uma nomenclatura diferenciada. Alguns itens da avaliação do ensino superior sofreram modificações, incluíram-se itens bons e itens novos. No caso do Enade, por exemplo, a prova deixou de ser obrigatória e assumiu um caráter amostral. É possível trabalhar com amostragem, mas quais as garantias que se pode ter de que o aluno realizará a avaliação com a mesma intensidade, com a mesma dedicação. Sendo obrigatório, todos sabiam que havia um documento que podia ser solicitado no futuro. 
Por isso, a necessidade de se dedicar. No processo de amostragem, alguns se dedicarão, mas não há como assegurar que todos terão o mesmo empenho para que se possa comparar uma amostra com a outra. A minha principal crítica às mudanças realizadas no processo de avaliação do ensino superior é seu caráter amostral.

- Everaldo: Houve, recentemente, uma mudança; retomaram o caráter transversal.

$\square$ Paulo Renato: Outra questão que aponto como problemática foi a mudança para três anos. Creio que o sistema ainda é muito novo no Brasil para espaçar tanto uma avaliação da outra. Era preciso continuar um pouco mais com a periodicidade anual ou a cada dois anos para que não houvesse instituições de quatro, três anos sem serem avaliadas. Questiono, também, a própria divulgação dos resultados. Publicávamos com os resultados do Provão toda a qualificação do corpo docente de cada curso, a dedicação, etc. Esse panorama deixou de ser feito.

- Everaldo: Agora houve uma retomada com o IGC. Chegaram, inclusive, a condenar sua gestão porque alegaram que havia ranking.

$\square$ Paulo Renato: É. Mas nunca fizemos ranking. Divulgávamos os dados, e alguns setores faziam uma lista. Não tínhamos como controlar esse tipo de situação. Esse governo, sim, faz ranking. Faz, inclusive, a partir do Enem. É um absurdo! Se eu fosse dono de faculdade ou de escola de ensino médio mal avaliada, entraria com um processo. Não há como comparar as notas de duas escolas sem avaliar o contexto em que se inserem. Como comparar amostragens se em uma escola 10 fizeram a prova e em outra $100 \%$ fizeram? Quer dizer, não podem fazer ranking a partir apenas do resultado que divulgam.

- Everaldo: Em um momento de seu livro, há a citação de uma carta, recebida do Banco Mundial, do FMI, que falava sobre a revolução gerenciada. Muito se ouviu que o governo e o Ministério da Educação sofriam influência do Banco Mundial. O senhor poderia comentar algo sobre isso?

$\square$ Paulo Renato: A carta justamente contraria essas afirmações. Em primeiro lugar, nem o Banco Mundial, nem o Fundo Monetário têm um programa sistemático. $\mathrm{Na}$ verdade, eles observam várias experiências, inclusive a nossa, com atenção e implantam em outros lugares. Se houve uma influência foi nossa para com eles. Esses órgãos financiavam algumas ações, tinham critérios a serem observados, mas nós não aceitávamos todas as condições que apresentavam. Eles queriam, na questão do livro didático, por exemplo, que fizéssemos licitação internacional. Nunca fizemos, sempre escolhemos o livro didático com os nossos próprios critérios. E assim ocorreu com uma série de recomendações. Eles nos ajudavam e disso não há nenhuma dúvida. Quando assumi o ministério, tínhamos dois empréstimos imensos que perfaziam um total de 800 milhões de dólares mais a contrapartida local. O valor estava intacto, o governo não tinha conseguido desembolsá-los. Nós não só os desembolsamos como contratamos mais dois, ou seja, tivemos um apoio financeiro muito grande do Banco Mundial, mas isso em nenhum momento significou qualquer tipo de influência. A política educacional foi definida pela equipe ministerial e existe até hoje. Veja, assumi a Secretaria de Educação e continuei o que estava sendo feito porque a equipe que trabalha lá é a mesma que veio do MEC.

- Everaldo: Como o senhor vê a expansão das instituições e a compra de parte delas pelo capital estrangeiro?

Paulo Renato: Enquanto estive no ministério, não aconteceu nenhum caso. É que, digamos, isso ocorre pela própria facilidade do mercado. Naquele momento, estávamos em uma grande expansão. Então, se olharem o número de instituições criadas, perceberão justamente que o número de instituições de ensino superior dobrou entre 1998 e 2003 . Ou seja, 50\% das instituições existentes em 2003 haviam surgido nos últimos cinco anos. E se observarmos o tamanho da instituição, metade delas tinha até 500 alunos. Eram pequenas, criadas especialmente no interior. Claro, naquele momento o movimento era de expansão. Agora há um processo de consolidação. Mas isso começou, diria, de 2004 para cá. A primeira incorporação de um grupo internacional foi em 2004, 2005. Acho que 2004. A primeira incorporação ocorreu entre o grupo financeiro Pátria, e a Anhanguera, em 2003. Na verdade, houve uma tentativa antes, o Pitágoras, mas não deu certo. O Pitágoras fez um modelo de 50/50 que não foi uma compra, mas uma associação. Não funcionou, sua estratégia de expansão foi equivocada. Tanto é que desfizeram depois. Voltaram a ficar sozinhos, recompraram a parte que havia sido vendida e, agora, fizeram uma nova venda para um fundo internacional. O Pitágoras já tinha vindo na minha época, mas não fazia parte desse processo de consolidação dos quais falo. Era mais uma associação. No modelo atual, o primeiro foi o Anhanguera, com o Banco Pátria, depois foi o Laureate, comprando o 
Anhembi, e, a partir dali, os dois se expandiram e entraram na bolsa. Também houve o lançamento de ações na bolsa. Fizeram parte desse sistema o COC, a Estácio, etc. São situações mais recentes em função de um processo de consolidação que seria natural, que ocorreu até em um ritmo mais lento do que esperávamos.

- Everaldo: Qual será, na sua percepção, o futuro desse panorama do ensino superior nos próximos anos?

$\square$ Paulo Renato: O processo de consolidação seguirá porque as instituições pequenas não têm condições de aguentar a concorrência. O que conseguimos colocar no sistema foi concorrência. Antigamente, o sistema era pequeno, altamente lucrativo. Hoje, as universidades estão ali, lutando, competindo em preço e qualidade. Quer dizer, o aluno, para fazer qualquer vestibular, pergunta qual é a avaliação da instituição e a mensalidade. É uma competição real que não havia antes. Como as instituições privadas dominavam o Conselho Federal de Educação, elas não permitiam a expansão, queriam lucros, eram monopólios brutais. Isso acabou. Tornamos a expansão do sistema de ensino superior mais flexível; no entanto, criamos a avaliação e, com isso, conseguimos, de certa forma, estabelecer certa concorrência e transparência.

- Everaldo: Nesse período não houve como fechar instituições?

$\square$ Paulo Renato: Tentamos, mas a Justiça não permitiu. Queríamos. Na época, 13 cursos passaram por todas as etapas da avaliação e não se saíram bem. Decidimos fechar e fomos impedidos por uma liminar na Justiça. Isso foi no último ano, e não houve tempo para tomar outras providências. $\mathrm{O}$ propósito da avaliação não é fechar, é fazer com que o sistema seja bom, que melhore. Mas tem de ter a possibilidade de fechar. Infelizmente, a Justiça não permitiu que fizéssemos isso, assegurou direitos, disse que não podia e coisa e tal. E teria sido uma discussão interessante de fazer se tivéssemos mais tempo. Acho que acabaríamos ganhando.

- Everaldo: Agora se fala em fechar 30\% das instituições.

$\square$ Paulo Renato: Penso que, se conseguirem, será bom. Mas o que o governo fez nesses últimos anos foi vincular o processo de credenciamento de novas instituições às corporações de ofício. Ou seja, as corporações que quisessem regular o exercício da profissão passavam a ter uma ação muito forte na expansão do sistema.
Everaldo: No governo de vocês já acontecia isso?

Paulo Renato: Não. Sempre deixamos muito claro que escutaríamos a $\mathrm{OAB}$, escutaríamos o Conselho Nacional de Saúde, mas a decisão seria nossa. Porque a $\mathrm{OAB}$ e o Conselho Nacional de Saúde têm todo o direito de regular o exercício profissional, mas não a criação de faculdades e a sua qualidade, essa é uma questão do Ministério da Educação. Por isso, o provão. Tive uma dificuldade muito grande em implantar o Provão na Medicina. Curioso! Foi o mais difícil. $\mathrm{Eu}$ quis implantar no primeiro ano e foi uma reação muito grande. Recuei. Queria no primeiro ano botar Direito, Medicina e Administração. A Medicina fez uma resistência brutal, então, abandonei-a e incluí a Engenharia Civil. Depois fui para outras engenharias. Quando o provão estava consolidado, conseguimos colocar a Medicina. Para o exercício da profissão, nesse sentido, o exame da OAB é legítimo. Creio até que eles têm de ser rigorosos mesmo. Porque ali eles veem quem é que será advogado. Agora, bacharel em Direito é outra coisa. Porque há muito bacharel em Direito tocando negócios e fazendo com competência. Qual é o problema. Nem todos que se formam em Direito precisam ser advogados. Quando me falavam disso, dava sempre o exemplo do filho do Kennedy, John John Kennedy, o que morreu naquele acidente aéreo. O JJK estudou Direito na Universidade de Harvard e nunca conseguiu passar para a Association. Nunca. Não tinha licença de advogado e era formado em Harvard. O filho do Kennedy. Não passava no exame. Nos EUA, um médico tem de fazer o exame a cada cinco anos, caso contrário perde a licença de exercício profissional. Ninguém vai tirar a formação dele. Formou-se em Medicina, mas o exercício profissional lá é por especialidade e o exame vale cinco anos. No Brasil, os médicos não têm coragem de botar um exame de exercício profissional por causa do próprio corporativismo. Não querem brigar com os colegas. Eles se protegem. Mas querem que alguém vá lá regular a profissão para eles. Não está certo. $\mathrm{O}$ Conselho Federal de Medicina existe justamente para fiscalizar a profissão e, verificando problemas, tomar as devidas providências, inclusive cassar registros se for necessário.

Everaldo: Professor, agora que o MEC deu abertura para que essas associações tomassem parte do processo, qual é a perspectiva futura?

$\square$ Paulo Renato: Acho que é voltar um pouco ao que a gente tinha. Não era afastá-los totalmente, colocálos num cargo opinativo, não deliberativo, como é hoje. A questão do exercício profissional no Brasil é uma questão muito complicada. Quando fui ao 
congresso defender o Provão, foi uma polêmica danada, fui várias vezes lá para audiências públicas. Tínhamos tramitando ao mesmo tempo a LDB e um de seus artigos, o primeiro a cair em discussão, de autoria de Darci Ribeiro, estabelecia o livre exercício profissional, salvo Medicina, Direito e Engenharia. Ao afirmarem que o Provão não funcionaria, eu dizia: "Não querem o provão, tudo bem. Mas aprovem aquele artigo da LDB, assim não haverá necessidade de uma avaliação desse tipo". O Provão se tornou necessário porque diploma tem valor econômico e precisamos ter um critério objetivo de qualidade. Agora, se não for isso, se o exercício profissional for livre, cada um vai fazer o curso que quiser e o mercado aceita quem quiser. O governo não precisa regulamentar. É assim nos EUA. Lá não existe diploma como temos no Brasil. Eles exercem a profissão, claro, Medicina tem regulação, Direito tem regulação, os próprios jornalistas têm uma norma, mas não é curso de Jornalismo, têm uma espécie de sindicato, em que se está registrado como sidicater, como é chamado lá, mas você não precisa de diploma.

- Everaldo: O mesmo ocorre com outras profissões nos Estados Unidos, por exemplo, para a Contabilidade é só fazer a prova e assinar o balanço no sindicater.

$\square$ Paulo Renato: Mas você passou no processo, foi registrado com um código. É um sistema de credenciamento basicamente. Economista, precisa ser uma profissão regulamentada. Eu sou economista. Meu filho fez Economia nos EUA. Quando chegou aqui, para registrar o diploma, precisou fazer duas matérias. Já era economista formado e com diploma. Já tinha pós-graduação na França, chegou aqui e teve de fazer duas matérias para ter o diploma de economista no Brasil. E isso que foram camaradas, e a USP deu apenas duas disciplinas.

- Everaldo: Muitos afirmaram que durante o período em que vocês estiveram no poder a educação virou uma espécie de mercadoria. O que o senhor pode dizer sobre isso?

$\checkmark$ Paulo Renato: Primeiro, quero deixar claro que nunca pensamos em privatizar as universidades federais. Até porque, convenhamos, quem é que compraria esses monstros, quem ficaria com todos os direitos dos professores, carga horária, etc.

- Everaldo: Quem compraria, compraria um grande passivo, é isso?

$\square$ Paulo Renato: Só passivo. A educação como um serviço que se presta tem um custo. Ou a sociedade paga em conjunto ou as pessoas têm de pagar. As federais não são gratuitas. Alguém paga, alguém arca com o custo. O que aconteceu no mundo, nos últimos anos, foi que a educação se transformou num valor. Para mantê-lo ou aumentá-lo, é preciso estudar permanentemente. Então, o que você chamou de mercado de educação é infinito. Por isso, surgiu o interesse dos capitais, dos grupos, dos fundos de investimento pela educação. Ela é um mercado infinito. Sempre se precisará dela. Não há limites, nesse momento, e sua trajetória é contínua. No passado era diferente. Há 25, 30 anos, ficava-se nos bancos escolares até certa idade. Depois, a formação seria aplicada durante toda a vida. Se um cidadão, por exemplo, chegasse aos 20 anos analfabeto, ele seria analfabeto para o resto de sua vida. O mesmo exemplo se aplica aos que tinham o primário [ensino fundamental], ou um diploma universitário. Hoje é diferente, qualquer pessoa precisa atualizar-se permanentemente. Precisa fazer curso, treinamento, enfim, aperfeiçoar-se. Por que existem as universidades corporativas, ou melhor, o que é uma universidade corporativa? É justamente a promoção, pela empresa, de oportunidades para a atualização, aperfeiçoamento de seus funcionários. Isso vale para as questões específicas de sua profissão e para as questões de formação mais geral. Por isso, atraiu o interesse de grupos, de fundos de investimento. Eles investem tentando obter algum tipo de retorno econômico. Não vejo nisso nenhum problema! Há uma demanda crescente e infinita, há o investimento desses grupos e, consequentemente, há um retorno. Mesmo que sejam grupos sem fins lucrativos, algum tipo de retorno terá, não necessariamente financeiro. Por exemplo, nos Estados Unidos existem instituições que são sem fins lucrativos, muitas delas de ensino superior, como Harvard, Yale, Preston. Veja o caso de Harvard. O fundo de investimento deles, resultado do excesso de investimentos, é uma fortuna, algo em torno de bilhões de dólares. Inclusive, com esta crise, perderam uma monstruosidade porque estava tudo investido. Acabaram perdendo muito. É uma universidade sem fins lucrativos, mas presta serviços, cobra pela sua educação e investe o excedente.

- Everaldo: Também é preciso considerar que as universidades públicas não atendem à demanda.

$\square$ Paulo Renato: Sim, em virtude do modelo. Pensemos na questão da pesquisa. Não se vai financiar pesquisa apenas para melhorar e ampliar o ensino. Para isso é preciso apoio financeiro do governo. Como existe nos Estados Unidos. A Nasa, o Departamento de Defesa, 
o Departamento de Saúde financiam grandes volumes de pesquisa nas universidades. As próprias empresas privadas contratam pesquisas.

- Everaldo: Mas lá há instrumentos legais para facilitar esse tipo de aplicação, não?

$\checkmark$ Paulo Renato: Sim, há instrumentos legais para facilitar esse processo.

- Everaldo: Pergunto porque aqui no Brasil não se consegue fazer isso. Por exemplo, uma indústria decide contratar uma universidade para que se realize uma determinada pesquisa. Nesse momento começam os problemas. Primeiro: se esse processo for considerado como serviço contratado, a pesquisa terá de ser tributada. Nisso já se perdeu $34 \%$ da receita, ou seja, o próprio governo, o próprio sistema acaba reaproveitando o investimento da iniciativa privada na universidade que poderia ser um bem comum.

P Paulo Renato: Por isso defendo a perspectiva de que possam existir entidades de ensino superior voltadas apenas para o ensino. Há instituições que fazem apenas ensino e o fazem muito bem. Quando era reitor da Unicamp, via essa questão da indissociabilidade do ensino, pesquisa e extensão de que muito se fala como uma necessidade vinda de uma relação de conjunto, de sistema, mas não que fosse necessário, ou possível, que em cada unidade se ensinasse o que suas pesquisas desenvolveram Não existe isso! Quer dizer, você precisa ter uma comunidade acadêmica que possa verificar o que do produto de pesquisa servirá para o ensino. Mas não manter no âmbito de cada instituição a indissociabilidade entre pesquisa, ensino e extensão.

- Everaldo: Será que não estariam faltando regras para que houvesse injeção de capital privado nas universidades privadas para que pudessem desenvolver pesquisa também? É muito fácil, muito cômodo dizer que nas privadas não há pesquisa e nas públicas há. A pública é financiada por ente mantenedor com milhões de reais na conta. A privada vive de mensalidade e, como o senhor mesmo comentou, sempre no fio da navalha. Então, será que uma forma de criar empregos, promover pesquisa privada, enfim, fazer a máquina girar não seria estimular os investimentos por meio de uma regulamentação?

$\square$ Paulo Renato: Sem dúvida! Poderia haver um estímulo ao desenvolvimento científico e tecnológico, mediante, por exemplo, a definição de determinados tipos de investimentos em ciência e tecnologia, em educação, etc. No entanto, não há. Os órgãos de financiamento da pesquisa no Brasil são órgãos públicos que, em geral, não sempre, tendem a privilegiar a própria instituição pública. Aqui em São Paulo, a Fapesp faz alguma coisa para as privadas, mas é, ainda, inexpressivo. Quando era ministro da Educação, até pensava nessa questão, mas infelizmente não se consegue fazer tudo. Quando se está operando a máquina pública, é necessário atender às questões mais urgentes, estabelecer prioridades. Eu precisava criar um sistema de avaliação e divulgálo. Não havia como pensar em montar um sistema de financiamento à pesquisa simultaneamente. Mas acabamos por elaborá-lo, afinal, porque criamos fundos de financiamento da pesquisa com as contribuições das empresas privatizadas. Esses fundos, em princípio, eram gerais, não atendiam apenas às universidades públicas. Mas isso já foi no final do governo, pois antes não houve tempo hábil para isso.

- Everaldo: Por que não há no Brasil uma agência reguladora para essas questões educacionais?

Paulo Renato: Nós pensamos nisso. O problema é o seguinte: qualquer agência reguladora seria, naquele momento, no caso das instituições de ensino, mais fraca do que o ministério, ou seja, ela não teria tanta força quanto o ministério. $\mathrm{Na}$ verdade, houve uma tentativa nesse sentido com o Conselho Federal de Educação. Nele, instituições privadas participavam. A questão é que acabou se tornando uma ação entre amigos, um sistema protecionista. "Não deixo expandir porque não quero concorrência, ou, então, para expandir quero uma parte na sociedade." Houve muitos casos assim durante a vigência do conselho. No sistema de ensino superior não estamos preparados, ainda, para ter uma agência reguladora. Talvez no momento em que haja uma consolidação do ensino superior fique mais fácil. Aproveitando, quero frisar que, quando se fala em investimento estrangeiro e ensino público, investimento em bolsas, etc., há uma transparência nas contas da instituição. Isto é, quando uma instituição vai para a bolsa de valores, torna-se transparente. Isso as pessoas não observam. Os acionistas minoritários têm de ter acesso a todas as suas políticas, às suas contas, a todas as informações e isso faz com que sejam transparentes, de domínio público. Quando a instituição é familiar, a situação é mais delicada porque há um dono que faz o que acha conveniente. É uma empresa limitada, não presta contas. Quando a instituição tem ações na bolsa, é aberta, precisa seguir as regras do mercado. Nesse caso, passa a ter mais transparência e se sabe 
exatamente qual é sua lucratividade, mais até do que as próprias instituições públicas.

- Everaldo: Quem teve acesso aos prospectos, tanto da Anhanguera quanto da Estácio, e entende um pouco do processo, constatou que as promessas eram enormes, estratosféricas. Trabalho em um centro universitário privado e sei exatamente como tudo funciona. Já sabia que as promessas daqueles prospectos não eram viáveis e, de fato, não foram concretizadas.

- Paulo Renato: Quando deixei o governo e montei essa empresa para assessorar as instituições, comecei a ter mais contato com o setor privado. Fiquei realmente muito impactado com o baixo nível de profissionalização da gestão. Nenhuma instituição possuía auditoria externa, feita por uma empresa de auditoria respeitável. Os diretores tinham um contador amigo e diziam que ele era o auditor. Nenhuma auditoria externa. Teve um caso, inclusive, de um grupo internacional que se reuniu com uma instituição, uma universidade daqui, de tamanho razoável para a época. Perguntaram sobre o auditor externo. A resposta foi que não havia. $\mathrm{O}$ grupo quis saber, então, como faziam. Os gestores disseram que deduziam as despesas da receita e o que sobrava era o lucro. Ou seja, não havia o devido conhecimento e controle.

- Everaldo: Esse tipo de situação não ocorre porque muitos donos de instituições de ensino superior vieram da área da educação?

口 Paulo Renato: A maioria eram professores ou ex-padres, que largaram a batina e, como sabiam lecionar, montaram um colégio. A partir desse colégio cresceram e agora temos grupos muito bons, sérios, que nasceram do mesmo jeito. O grupo Positivo, por exemplo, nasceu como um cursinho pré-vestibular. O Objetivo também, mas ainda mantém o sistema de estrutura familiar. O Positivo não. Tem os sócios e hoje é uma potência.

- Entrevistador: A qualidade do Positivo é uma coisa impressionante, não apenas a qualidade intrínseca e a externa, mas as próprias construções para os alunos, o material didático, tudo.

- Paulo Renato: É verdade. E foi um grupo que nasceu com cinco professores que se juntaram, fizeram o cursinho e deu certo. Mas a origem explica uma parte, não explica tudo. Os cinco sócios têm a minha idade. Foi na época que entrei na faculdade, no final dos anos 1960. Todos eram universitários. Como começou a haver uma grande oferta de alunos terminando o ensino médio, os vestibulares passaram a ficar muito competitivos. Então, esses alunos, que já estavam na faculdade, criavam cursinhos prévestibulares. Isso aconteceu por todo o Brasil e, se olharmos a origem de muitos grupos que hoje são fortes na educação, Porto Alegre, Curitiba, São Paulo, Minas Gerais, todos nasceram assim. Alguns se mantiveram fazendo exatamente a mesma coisa e outros partiram para a expansão. Depende muito da capacidade empresarial dos sócios ou de um dos sócios que assumiu a liderança do empreendimento.

- Everaldo: Em sua visão, qual é a perspectiva para o ensino superior no Brasil e no mundo?

Paulo Renato: Creio que seguirá esse processo de capitalização e de expansão do ensino superior, mas não tanto como um ensino superior tradicional de graduação e muito mais como uma educação continuada. Nesse sentido, ocorrerá uma diversificação, inclusive, das instituições. Considero muito importante o que está acontecendo nas grandes empresas, com a formação das universidades corporativas para as quais olhamos com o nariz torcido, mas que fazem parte do sistema educacional. Tomemos, por exemplo, uma universidade corporativa da Vale, da Petrobras, ou outras instituições, como o Banco do Brasil, o antigo departamento de treinamento cresceu em função dessa necessidade de atualização permanente da qual falei antes e contratou instituições para a formação de seus profissionais. Na Vale, tem curso contratado com MIT, Harvard, USP, COC do Rio de Janeiro e escola técnica. Não é ela que tem seus professores, não é uma universidade nesse sentido. Ela coordena um esforço de muitas instituições para atingir um objetivo seu, direcionado para os seus funcionários. Há dois anos, faço a abertura do MBA corporativo da Ambev, que é realizado na São Paulo Business School. Eles contrataram a São Paulo Business School e oferecem um MBA para seus gerentes. É um MBA de liderança empresarial e com tendências do mundo econômico para a formação de executivos. Fazem-no com o objetivo de formar seus futuros diretores.

- Everaldo: - É um programa de divisão futura de negócios - E como o senhor vê o ensino a distância?

Paulo Renato: Vejo como algo muito importante para essa educação permanente de que falo e para a aproximação do mundo da educação ao mundo do trabalho. A educação a distância passa a ser um instrumento essencial porque se vale da autonomia, da gestão de tempo. 
- Everaldo: Já havia algum projeto em relação à $\mathrm{EaD}$ em sua gestão?

a Paulo Renato: Havia sim. Foi uma briga conseguirmos a aprovação. Nós regulamentamos a EaD. Primeiro, estabelecemos que $20 \%$ de toda a carga horária do curso poderia ser a distância. Queríamos, com isso, quebrar a resistência. E, na sequência, passamos a credenciar instituições puramente a distância. Foi nesse momento que surgiu o primeiro obstáculo: conseguimos aprovar para a graduação, mas não para a pós-graduação. Tivemos de deixar de fora o decreto do Ensino a Distância para pós-graduação. Embora já divulgado, ainda há um preconceito muito grande em relação ao ensino a distância. Só que, se formos buscar exemplos, encontraremos a Open University da Inglaterra, que é uma das melhores universidades inglesas em termos de qualidade e não tem aluno presencial. É totalmente a distância. Com um detalhe, existe há décadas e antes não havia tecnologia, eles faziam por correio, papel. Da mesma forma, o Instituto Universal, aqui no Brasil, que formou muita gente para o mercado de trabalho. Por isso, vejo com muita expectativa a expansão da $\mathrm{EaD}$ em nosso país.
Submetido em: 26/07/2015

Aprovado em: 17/02/2016 